\title{
Discharge of water containing waste emanating from land to the marine environment: A water quality management perspective
}

\author{
SHH Oelofse ${ }^{1}$, P Viljoen ${ }^{1}$, S Taljaard $^{2}$ and WAM Botes ${ }^{3}$ \\ ${ }^{1}$ Department of Water Affairs and Forestry, Private Bag X313, Pretoria 0001. South Africa \\ ${ }^{2}$ CSIR, Environmentek Stellenbosch. South Africa \\ ${ }^{3}$ WAM Technology cc. South Africa
}

\begin{abstract}
The National Water Act, 1998 (Act 36 of 1998) mandates the Department of Water Affairs and Forestry to manage all water containing waste (wastewater), which emanates from land-based sources and which directly impact on the marine environment. These sources include sea outfalls, storm water drains, canals, rivers and diffuse sources of pollution. To date there are many places where wastewater is being discharged into the sea. More than forty sea outfalls are formalised through authorisations issued in terms of the old Water Act, 1956 (Act 54 of 1956) and the National Water Act, 1998 (Act 36 of 1998). In order to protect water quality, effluent standards were applied under the old Water Act to discharges into the water resource. However, the National Water Act, 1998 follows a receiving water quality objectives approach recognising differences in the assimilative capacity of different resources. Both approaches have the same main objective namely to maintain the resource at a quality fit for use by other users. The same principle applies to discharges to the marine environment. In addition, South Africa, as a signatory to a number of international Conventions and treaties such as the London Convention, is committed to certain requirements pertaining to the disposal of waste at sea. To meet such requirements, a very clear policy on what could be allowed for discharge to sea is required for South Africa. Such a policy should be very clear on what is allowed, why it is allowed and the conditions that apply for such discharges in order for this country to retain international credibility.

In this paper the authors provide a concise discussion on:

- The development of an operational policy providing the strategic view on marine disposal, as well as the goal, basic principles, ground rules and management framework that will be applied to the discharge of land-derived wastewater to the marine environment; and

- Overview of procedures to guide authorities and managers in terms of the administrative and institutional responsibilities in dealing with land-derived wastewater discharges to the marine environment of South Africa.
\end{abstract}

\section{Background}

A wide variety of pollutants and waste, both from point and nonpoint sources enter marine ecosystems, largely through the medium of water. This has adverse effects on coastal ecosystems and possibly human health. Coastal activities should be planned and managed to ensure that pollution and waste do not compromise opportunities for sustainable coastal development (DEAT, 2000a). The growing demand on the utilisation of our water resources requires that the Department of Water Affairs and Forestry (DWAF) reconsiders their management of the disposal of wastewater in coastal areas, especially in light of international trends and requirements.

The DWAF as public trustee of the water resources in South Africa must ensure that water is protected, used, developed, conserved managed and controlled in a sustainable and equitable manner. In order to protect water resource quality, strict measures such as standards and Resource Quality Objectives are applied to discharges into the water resource, the main objective being to maintain the resource at a quality that is fit for use by other users. The same principle applies to discharges in coastal areas, especially

This paper was originally presented at the 2004 Water Institute of South Africa (WISA) Biennial Conference, Cape Town, South Africa, 2-6 May 2004.

* To whom all correspondence should be addressed.

唺+2712 336-7549; fax:+2712323-0321; e-mail: OelofseS@dwaf.gov.za since coastal areas are at the bottom end of catchments and directly impacts on the quality of marine resources.

Discharge of wastewater to the sea is an additional disposal option in coastal areas, on condition that the marine environment will remain fit for use by its other users. Discharges of wastewater to the water resource in inland areas have to meet certain standards in order to meet predetermined resource quality objectives set for the receiving resource. Resource Quality Objectives (RQOs) are management objectives that are set taking into account the quality requirements of the reserve as well as other users. Meeting the set RQOs will thus ensure that the resource remains fit for use by its other users. Along the same lines, when wastewater is discharged into the sea, the sea must remain fit for use by its other users; therefore discharges should be of such quality that the guideline values as contained in the Water Quality Guidelines for Coastal Marine Waters (DWAF, 1995) will be met outside the predetermined mixing zone of the discharge. The Water Quality Guidelines for Coastal Marine Waters are being used to assist in setting sitespecific water quality objectives for the marine environment. However, the setting of objectives for marine water quality is outside the mandate of the DWAF.

\section{International conventions (e.g. London Convention)}

South Africa is a signatory to the London Convention (International Maritime Organisation, 1972) and the 1996 Protocol thereto. 
The 1996 Protocol placed a ban on the dumping of certain substances in the sea and restricted others because of the limited capacity of the sea to assimilate waste and render them harmless. The Convention does however recognise that States have, in accordance with the Charter of the United Nations and the principles of international law, the sovereign right to exploit their own resources pursuant to their own environmental policies, and the responsibility to ensure that activities within their jurisdiction or control do not cause damage to the environment of other States or areas beyond the limits of national jurisdiction. The Convention also notes that marine pollution originates from many sources such as dumping and discharges through the atmosphere, rivers, estuaries, outfalls and pipelines, and that it is important that all states use best practicable means to prevent such pollution and develop products and processes which will reduce the amount of harmful wastes to be disposed of. It is therefore important to note that the Convention does not regulate the discharge of waste through sea outfalls as this activity is specifically excluded from their definition of dumping. It will however be contradictory if a party state does not apply similar principles to sea outfall discharges than is applied to dumping activities.

The Global Programme of Action for the Protection of the Marine Environment from land-based Activities (GPA) (United Nations, 1995) should also be mentioned here. The GPA recognise that freshwater (including groundwater), the coast and the sea are inseparably linked and ask that conflicting interests over the seas, coasts and river basins be resolved through integrated management of resources and environmentally sound economic development. The Department of Environmental Affairs and Tourism is the lead agent in the development and implementation of a National Programme of Action for South Africa.

\section{Marine disposal option}

The geographical location of South Africa and the favourable ocean currents in the area does however make marine disposal along the $2954 \mathrm{~km}$ coastline a very attractive and in some instances a viable option. Site-specific oceanology of the coastal waters, including geology and hydrography, currents, tides and the sensitivity of the marine environment could however be limiting factors.

There are therefore a definite need for a clear operational policy on the effluent/wastewater which could be allowed to be discharged through a sea outfall pipeline to the marine environment, clearly specifying/outlining circumstances and outlining certain conditions that should be applied to such discharges in order for this country to retain international credibility as signatory to a number of international conventions and treaties, e.g. the London Convention.

The implications of the above statements are twofold. The first being the prevention of pollution, this requires that the capacity of the sea to assimilate waste must not be exceeded; the second being the reduction at source (precautionary approach) in the amount of harmful waste through processes such as cleaner technology, waste minimisation, recycling and reuse.

\section{Water resource management issues}

The water used in coastal areas is abstracted from a water resource or the sea, used and the resulting water containing waste needs to be discharged. In this regard there is a requirement in terms of Section 22(2)(e) of the National Water Act, 1998 (RSA, 1998) to return any wastewater to the water resource from which it was taken, unless the responsible authority (DWAF) directs otherwise or the authorisation provides otherwise. The efficiency of the water use is another important issue for resource management and therefore, both the abstraction or intake and the discharge needs to be managed.

DWAF also has a direct interest in the volumes of freshwater being discharged through sea outfalls since it has a direct impact on the flow through estuaries. The National Water Act, 1998 provides for a classification system, reserve (quantity and quality requirements for basic human needs and the aquatic ecosystem) and resource quality objectives generally referred to as resource directed measures aimed at providing water resources the necessary level of protection in order for the resource to remain fit for use by other users. Effect must be given to the reserve when exercising any power or performing any duty in terms of the NWA (Section 18). Freshwater being discharged to sea through sea outfalls can therefore have a serious impact on both the quality and quantity requirements of an estuarine reserve.

South Africa, being a water scarce country, has to optimise the use of its freshwater resources. Water conservation and demand management strategies are being developed as part of the National Water Resources Strategy and Catchment management strategies. These strategies focus on the optimisation of efficient water uses. When it comes to discharging wastewater (freshwater containing waste) to sea, the test to pass is whether the water could not be treated and re-used for another beneficial water use instead of being discharged. This especially becomes relevant in water stressed areas where transfer schemes or desalination plants for the desalination of seawater has to be investigated to augment current shortages in supply. Every possible effort should have been taken to optimise the use of all available water in a catchment before augmentation schemes could be considered.

\section{Source management issues}

The same hierarchy of decision taking in water quality management as applied to inland discharges will be applied to discharges to sea:

- Pollution and waste should be prevented where possible

- Minimise all unavoidable waste and pollution at source

- Apply a precautionary approach to the disposal of any unavoidable waste with the proviso that the environment can assimilate the waste load

- Site-specific interventions such as stricter discharge standards will be enforced where the environment cannot assimilate the waste load

\section{Strategic view on marine disposal}

The DWAF's strategic view on the treatment and disposal of landderived wastewater to the marine environment is as follows:

Responsible disposal of land-derived water containing waste (also referred to as wastewater) to the marine environment is an option in the South African context due to the geographical location of the subcontinent and the generally favourable, dynamic physical conditions along the coastline (site specific conditions determined, for example by geology, tides, currents and waves are limiting factors that must be taken into account).

However:

- Because South Africa is a water scarce country, the loss of freshwater to the marine environment must be limited in terms of water conservation and demand management strategies.

- According to the White Paper on a National Water Policy for South Africa 'efforts to introduce source control will be strength- 
ened, through permits and standards and through changes in technologies and land-use, with the final aim of getting as close as possible to a situation in which there is no discharge of pollutants into our water (including the marine environment)'.

- Evaluation of the treatment and disposal of land-derived wastewater to the marine environment will be undertaken in accordance with the Basic Principles, Ground Rules and Management Framework stipulated in the operational policy for the treatment and disposal of land-derived wastewater to the marine environment. These underpin, for example the principles of integrated environmental management (IEM).

\section{Operational policy}

\section{Purpose}

To fulfil its legal obligation in terms of the management and control of land-derived wastewater, the Department of Water Affairs and Forestry commissioned a project to develop an operational policy specifically focussing on the treatment and disposal requirements of land-derived wastewater to the marine environment of South Africa.

\section{Approach}

Globalisation is a reality and although South Africa may not always be able to afford first world approaches, it is important to strive for higher standards. The reality of exporting industries competing in the international market where first world standards apply should not be ignored.

The approach that was followed deriving the operational policy for the treatment and disposal of land-derived wastewater in coastal areas were as follows:

- International and national policies and legislation were reviewed to provide a sound base and to ensure that the operational policy is strongly aligned with South Africa's overarching obligations and commitments (both international and national) in pollution control and waste management in the marine environment.

- International trends pertaining to treatment and disposal of land-derived wastewater to the marine environment were followed on recommendation of the Project Steering Committee.

- Operational policy that was previously applied in South Africa, e.g. under the previous Water Act 56 of 1954 and the track record of the performance of marine disposal activities in South Africa over the past years were considered.

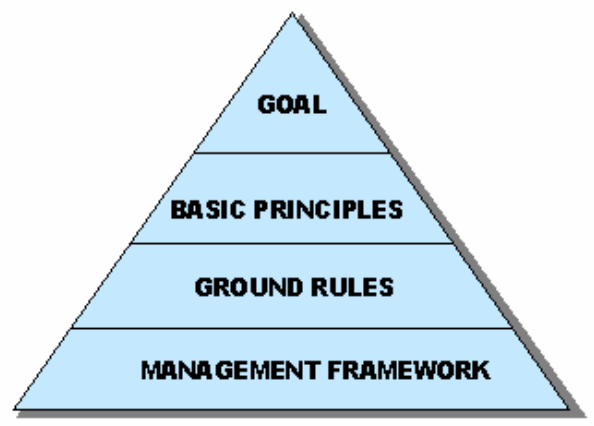

Figure 1

The structure of the operational policy for treatment and disposal of land-derived wastewater to the marine environment of South Africa
- New and improved technological and scientific developments pertaining to treatment and disposal of land-derived wastewater to the marine environment, both locally and internationally were also considered.

The draft policy was subjected to public participation at workshops and via the Internet site http://www.wamsys.co.za/outfalls. Before finalisation it will also be peer reviewed by national and internal experts in the field.

\section{Goal}

'Achieving water quality that is 'fit for use' and maintaining aquatic ecosystem health on a sustainable basis by protection of the country's water resources (including marine waters), in a manner allowing justifiable social and economic development'

\section{Principles and ground rules}

Basic principles and ground rules were developed based on International policies and in line with other National Government policies such as the White Paper on Integrated Pollution and Waste Management for South Africa (DEAT, 2000b) and the White Paper on Sustainable Coastal Development in South Africa (DEAT, 2000a).

Ground rules are derived within the broader reference framework of the Basic Principles and provide more specific rules that will be applied by Government when, for example considering licence applications to dispose of land-derived wastewater to the marine environment. For the operational policy, the Ground Rules are addressed under specific themes considered to be of particular relevance in the treatment and disposal of land-derived wastewater to the marine environment namely:

- Local Management Institutions

- Legislative Requirements

- Receiving Marine Environment (including sensitive areas, environmental quality objectives and initial mixing zone)

- Development/Activities and associated waste loads (including municipal/urban wastewater, industrial wastewater and urban stormwater runoff)

- Scientific and Engineering Assessment

- Monitoring and Contingency Planning.

\section{Management framework}

To successfully implement the basic principles and ground rules for the treatment and disposal of land-derived wastewater to the marine environment in a systematic, structured and cost-effective manner, a practical management framework is required. Logical components that need to be addressed as part of such a management framework include:

\section{Management platform}

Establishment of a local management institution that will be able to 'drive' the management process and that will supervise effective implementation

\section{Legislative framework}

A management framework needs to be designed and implemented within the international and national legislative framework governing the particular activities and affected environmental domains. For the treatment and disposal of land-derived wastewater to the marine environment these requirements are provided in the Basic Principles and Ground Rules of this operational policy. 
Study area boundaries, important marine ecosystems, beneficial uses and environmental quality objectives

The study area within which this management framework needs to be applied must be determined, taking into account the 'footprint' of anticipated influence of the proposed discharge both in the near and far field (e.g. an entire bay or ecosystem). Environmental quality objectives need to be set in consultation with stakeholders. The identification and mapping of sensitive marine ecosystems in the affected areas and the beneficial uses provide the basis for the derivation of such site-specific environmental quality objectives. For environmental quality objectives to be practical and effective management tools, these need to be set in terms of measurable target values or ranges for the specific water column, sediment and biological parameters related to the effluent composition.

\section{Developments/activities and associated waste loads}

To ensure that cumulative effects are taken into account, the waste loads of the development/activity under investigation, as well as those of existing waste inputs to the study area (both in terms of quantity and quality) need to be defined. Even though this policy focuses on the disposal of land-derived wastewater, it is important to ensure that the disposal practice be evaluated in the context other waste inputs and anthropogenic activities in the area to ensure that synergistic and/or cumulative interactions are addressed.

\section{Scientific and engineering assessment}

The objective of this component of the management framework is to refine the environmental quality objectives for a particular marine environment and to establish whether a waste disposal practice can be designed that will comply with such environmental quality objectives. The following is required:

- Characterising physical, biogeochemical processes and ecological functioning of the receiving marine environment,

- Selection of an outfall location (headworks and discharge location) and a conceptual hydraulic design of the outfall, based on preliminary required dilution estimates and taking into account characteristics of waste loads (both in terms of volume and composition,

- Determining achievable near and far field dilutions, as well as deposition/re-suspension patterns, taking into account other anthropogenic influences in the study area, as well possible synergistic or cumulative effects,

- Assessing for compliance to environmental quality objectives. Where compliance cannot be achieved through, for example adjustment of the hydraulic design or discharge location, either the critical limits for the waste load needs to be reduced (e.g. through additional treatment prior to discharge) or the environmental quality objectives need to be re-defined (only in extreme situations, e.g. in cases where economic/social gains justifies such environmental sacrifice) and

- Structural design and construction considerations of a marine outfall to meet requirements as determined by the above.

In conducting the scientific and engineering assessment component, numerical modelling techniques have proven to be powerful prediction 'tools'.

\section{Monitoring and contingency plans}

Long-term monitoring plans need to be designed and implemented to continuously evaluate the:

- Effectiveness of management strategies and actions to comply with limits contained in the licence conditions, such as discharge standards on volume and composition of the wastewater (Source or Compliance monitoring); and
- Determine the trends and status of changes in the environment in terms of the health of important ecosystems and designated beneficial uses in order to respond, where appropriate, in good time to potentially negative impacts, including cumulative effects. Also, to assess whether predicted environmental responses, made during the assessment process, match actual responses (Resource monitoring).

Contingency plans and mitigating actions are required to minimise the risks to the environment in the event of malfunctioning, both during construction and operation.

\section{Evaluation, reporting}

Monitoring programmes typically become part of the licence issued by the DWAF for a particular discharge under Section 21 of the NWA. These monitoring programmes are designed and implemented at the cost of the licensee (following the Polluter Pays Principle).

To be useful from a management perspective, monitoring data must be evaluated against pre-determined objectives. Results need to be presented in clear format, providing the appointed management institution/s with the scientific and engineering knowledge for effective decision making.

\section{Administrative procedures and institutional responsibilities}

Discharges of land-derived wastewater to the marine environment, which need authorisations in terms of the National Water Act, 1998 and will be subject to the Operational policy include:

- New discharges

- Existing lawful discharges

- Upgrades, extensions of existing wastewater treatment works or industries discharging directly into the marine environment that were not authorised as part of existing authorisations

- Changes in volume and/or composition of a discharge.

When a need for an authorisation has been established, there is certain procedure to follow in order to obtain the necessary authorisation. The process to be followed as well as an indication of the roles and responsibilities of all parties involved in an application is outlined for ease of reference.

\section{Guidance on implementation of operational policy}

To assist with the implementation of the operational policy, a document also has been prepared that provides practical guidance on the implementation of the management framework, in particular. Guidance is given on every step of the management framework. This document can be used by both to the authority having to take a decision on whether or not a discharge of land-derived wastewater to the marine environment could be allowed as well as to the designer and operator of a sea disposal system.

\section{Recommendations for future implementation}

It is recommended that South Africa keep a regularly updated inventory of waste discharges to the marine environment, both in terms of volumes and loads. This has become general practice in many countries and provides a sound base from where the effectiveness of an operational policy can holistically be assessed.

Another recommendation is to have a Code of Practice developed for specific industries in South Africa, specifically addressing 
ways in which to eliminate or minimise the production of waste, based on best available techniques. Codes of practise provide clear guidance to industries with regard to their environmental obligations in that sound technologies are specified. It also assists management authorities by providing them with guidance on the type of waste that will need to be handled from a particular industry. This source directed approach to waste elimination and minimisation is considered to be of great value. For South Africa, this could easily be adopted from available documentation used for example by Canada and New Zealand. The Source Management Strategy currently being developed by DWAF will also be a valuable resource in this regard.

Lists of prohibited and controlled substance should be developed and reviewed as the types of industries and their wastes streams becomes more clearly defined. Countries like Canada and New Zealand also include certain waste stream types in their lists. This is an approach to accommodate synergistic effects of complex effluents and should be investigated for the South African scenario.

The South African Water Quality Guideline series for coastal marine waters should be reviewed.

\section{References}

DEPARTMENT OF ENVIRONMENTAL AFFAIRS AND TOURISM (DEAT) (2000a) White Paper for Sustainable Coastal Development in South Africa (April) p 137.

DEPARTMENT OF ENVIRONMENTAL AFFAIRS AND TOURISM (DEAT) (2000b) White Paper on Integrated Pollution and Waste Management for South Africa, p. 61 (May 2000).

DEPARTMENT OF WATER AFFAIRS AND FORESTRY (DWAF) (1995) South African Water Quality Guidelines for Coastal Marine Waters. Volume 1-4, Pretoria, RSA.

DEPARTMENT OF WATER AFFAIRS AND FORESTRY (DWAF) (1997) White Paper on a National Water Policy for South Africa. p. 37.

INTERNATIONAL MARITIME ORGANISATION (1972) Convention on the Prevention of Marine Pollution by Dumping of Wastes and other Matter, London. p 63.

RSA (1998) Act No 36 of 1998: National Water Act.

UNITED NATIONS (1995) The Global Programme of Action for the Protection of the Marine Environment from Land-based Activities. 